\title{
The Effects of Emergency Housing on Wellbeing: Evidence from Argentina's Informal Settlements*
}

\author{
Ann Mitchell*, Jimena Macció*, Diego Mariño Fages** \\ *Department of Economics, Pontificia Universidad Católica Argentina, Buenos Aires, \\ Argentina, ** Department of Economics, Duke University, Durham, NC, USA
}

\begin{abstract}
The aim of this paper is to present evidence on the effects on wellbeing of providing a basic dwelling on-site to households living in situations of extreme poverty in urban slums. In particular, the paper evaluates the impact of the NGO TECHO's emergency housing programme in informal settlements of Buenos Aires, Argentina. Using a quasi-experimental pipeline approach, the paper shows that the programme has a large effect on privacy, security, interpersonal relations, psychological wellbeing and perception of quality of life. In health the program only produces a reduction in the prevalence of cough and congestion. While indicators of sleep quality improve, the effects are not statistically significant after adjusting for multiple hypothesis testing. Additionally, the programme increases the likelihood that households with school age children have a tranquil place to study, evidence that the programme could broaden children's long-term opportunities.
\end{abstract}

Keywords: housing, urban, slums, impact evaluation, Latin America

Acknowledgements: The authors would like to thank the following people for their valuable comments: María Laura Alzua, Roger Betancourt, James Copestake, Osvaldo Feinstein, Cythia Goytia, Patricio Millán, Ricardo Perez Truglia, Mariano Rabassa and two anonymous referees.

\section{Introduction}

Inadequate housing is one of the most critical problems facing Latin America today. Nearly $80 \%$ of the region's population lives in urban areas and close to a third of urban households have a deficit in either the quantity or quality of housing. Of the 130 million families living in the region's cities, 9 million live in a dwelling made of inadequate materials, 5 million experience overcrowding, 14 million have insecure tenancy and 21 million lack at least one basic service (electricity, water or sewerage) (Bouillon, 2012). Moreover, approximately 
one fifth of Latin America's urban population lives in an informal settlement or slum, enclaves characterized by a lack of access to public services, overcrowding, precarious housing and insecure tenancy (UN-Habitat, 2016).

* On behalf of all authors, the corresponding author states that there is no conflict of interest.

The broadening of access to adequate housing requires action on many fronts, including investments in public infrastructure, the development of financial markets that facilitate access to mortgage credit, adequate land use regulation, institutional reforms to regularize land tenancy and the support of actions at the community level (Bouillon, 2012; UN-Habitat, 2016). While some countries have made important advances in instrumenting integrated policies to improve habitat in Latin America (Bouillon, 2012), there continues to be a large deficit in the quality and quantity of housing, which affects disproportionately the poorest households (Rojas and Medellin, 2011).

Throughout the Global South low income families that are unable to purchase housing through the market construct their own dwelling on unoccupied land, a process that has led to the proliferation of informal settlements (Ortiz, 2011). The provision of emergency housing is one form of action taken by civil society organizations to improve living conditions in urban slums.

The aim of this paper is to present evidence on the effects on wellbeing of providing a basic transitory dwelling on-site to households living in situations of extreme poverty in urban slums. In particular, the paper evaluates the impact of the NGO TECHO's emergency housing programme in the informal settlements of Buenos Aires, Argentina. ${ }^{1}$ The evaluation is justified by the scale of TECHO's programme, which currently operates in 19 Latin American and Caribbean countries.

The paper builds on the work of two previous impact evaluations of the TECHO programme. The first was a randomized control trial conducted in El Salvador, México and Uruguay, which showed that the programme improved housing conditions, satisfaction 
with housing and subjective measures of quality of life and caused a small reduction in the incidence of diarrhoea in children in El Salvador and Mexico (Galiani et al., 2016). No effect was found on complementary housing investments, possession of durable goods, incidence of robbery, fertility, income or labour outcomes. The second was a smaller scale evaluation of the effect of the TECHO programme on sleep quality in the informal settlements of Buenos Aires (Simonelli et al., 2013). In that study, which used a beforeafter methodology, the authors found that the programme was associated with reductions in the level of dissatisfaction with housing and stress and improvements in indicators of sleep quality and perception of quality of life.

This paper measures the programme's effect on a wider range of wellbeing dimensions and employs both objective and subjective measures within each dimension. We find that the programme has a large and statistically significant effect on privacy, security, interpersonal relations, psychological wellbeing and perception of quality of life and a more limited effect on health, sleep quality and activities in the home. Moreover, the quasi-experimental pipeline approach employed in the paper serves as another example of a relevant strategy for practitioners who seek to measure causal effects when random assignment of treatment is not feasible. Earlier examples of this approach can be found in Coleman (1999), Bali Swain and Varghese (2009) and Deininger and Liu (2013).

The paper also seeks to contribute more generally to the assessment of the effectiveness of on-site slum upgrading programs (Jaitman and Brakarz, 2013). This research has shown, for example, that the provision of property titles increases the time spent on labour activities (Field, 2004) and housing investments and children's education (Galiani and Schargrodsky, 2010). An evaluation of a program to provide credit for the installation of private water connections in urban Morocco found that the program improved subjective wellbeing and social integration, but did not alter labour market 
participation, income or health (Devoto et al., 2011). Cattaneo et al. (2009) showed that a Mexican program to replace dirt with cement floors improved children's health and cognitive development and adults' quality of life and satisfaction with housing.

The paper is structured as follows. The second section describes TECHO's emergency housing programme. The third section reviews the literature on the relationship between housing and wellbeing and presents the criteria for selection of the outcome dimensions and indicators. The fourth section outlines the evaluation methodology and the household survey data. The fifth section presents the paper's main results. The sixth section assesses the robustness of the findings. The final section discusses the conclusions.

\section{TECHO's emergency housing programme}

TECHO's emergency housing programme provides a basic 18 square meter structure made of prefabricated wood panels and an insulated tin roof (Figure 1). The house is supported by 15 pilings that elevate the dwelling from the ground, shielding the floor from humidity and floods which are common in the settlements. The dwelling is built on the plot of land on which the household resides and does not provide water, sanitation, electrical connections or any other amenities. The cost of materials of each house is approximately US\$1,000. Groups of 4 to 8 volunteers build each dwelling, together with the future residents, in just two days.

Around a third of the beneficiary households use the TECHO house to replace their existing dwelling, half use it as an additional room and two in ten use it to separate nuclear families. When the TECHO house is used as an additional room the most frequent use is a bedroom. The use given to the dwelling varies depending on the household size, the size of the land parcel, the quality of the original dwelling and whether or not the family needs to dismantle part or all of their existing dwelling in order to make room for the new construction. 
To select the beneficiaries TECHO first conducts in each neighbourhood a detection survey which collects information on the sociodemographic characteristics of household members, the household's economic situation, housing characteristics and access to public services. This data is processed and used along with qualitative information to classify households according to their level of need. Those classified as high and medium-high need are eligible to participate in the programme. The families that decide to participate must first sign a contract in which they agree to pay approximately $10 \%$ of the cost of the house, attend preconstruction neighbourhood meetings and clear and prepare the plot of land. ${ }^{2}$

TECHO's emergency housing programme is targeted at the poorest households living in informal settlements. According to our evaluation's baseline survey nine out of ten households have income below the poverty line and half below the indigence line. ${ }^{3}$ Moreover, nine out of ten adults over age 24 have not completed secondary school and one out of four over 18-year olds are unemployed. All households have a severe deficit in either the quality or quantity of housing: half have less than $5 \mathrm{~m}^{2}$ of housing per person, one out of four has a dirt floor and 45 per cent has a dwelling that floods when it rains.

\section{Housing and wellbeing}

TECHO's emergency housing programme is designed to have a direct effect on both the size and quality of housing. The magnitude of these effects depends on the use given to the dwelling. Households that use the dwelling as an additional room are expected to experience a substantial increment in dwelling size but a more limited change in its quality, whereas those that use it to replace their existing dwelling are expected to experience only a marginal increase in size but a substantial improvement in quality.

There is a broad literature on the association between the size and quality of housing and diverse aspects of family and human life (Thomson et al., 2009). Deficient quality of 
housing construction and materials has been shown to negatively affect physical and psychological health, sleep, security and social relations. The health literature has tended to focus on the pathological effects of some aspect of housing, such as poor ventilation, insecure construction or the use of deficient or toxic materials (Newman, 2008). Humidity, mould and inadequate heating, for example, have been linked to respiratory problems in children (Peat et al., 1998; Benicio et al., 2004). Several longitudinal studies demonstrate that relocation to better quality housing was associated with improvements in measures of mental health, such as reduced depression and anxiety, and in relations with neighbours (Evans et al., 2000). Housing that does not provide adequate insulation from noise, heat, cold and wind can also reduce sleep duration and quality (Simonelli et al., 2015). Inadequate building design can produce risks to physical safety, allow the intrusion of external threats and diminish perceptions of security and control (Bonnefoy, 2007). Recent impact evaluations have shown the causal effect of housing improvements in informal settlements on health and perception of security (Cattaneo et al., 2007; Galiani et al., 2016) and sleep (Simonelli et al., 2013).

Another strand of the literature focusses on the effects of overcrowding. It is argued that people who live in small overcrowded dwellings tend to experience a greater amount of social demands and lack privacy in carrying out their daily activities, factors which negatively affect both psychological health and the quality of interpersonal relations (Gove, Hughes and Galle, 1979). Human responses to overcrowding, it is argued, include both withdrawal from social life as an escape from social overload and aggressive behaviour due to frustration and a reduction in freedom of choice (Regoeczi, 2002). ${ }^{4}$ Empirical studies have demonstrated the association between overcrowding and mental health (Gove, Hughs and Galle, 1979; Evans et al., 2000), lack of sleep privacy (Cardinall et al., 2014), and behavioural problems and low educational performance among children (Evans et al., 
1998; Solari and Mare, 2011) Moreover, overcrowded dwellings help foster the spread of disease (Fonseca et al, 1996; Murtagh et al, 1993).

Our review of this ample literature along with evidence on living conditions in Buenos Aires' informal settlements provided the criteria for selecting the following seven impact dimensions: privacy, sleep, health, security, activities in the dwelling, interpersonal relations and psychological wellbeing and perception of quality of life. The process of selection of the impact indicators within each dimension was guided by the lessons of the capability approach (Sen, 1999). We sought to select measures of wellbeing in the space of human functionings (to be free of disease, to feel secure, to experience privacy, to enjoy adequate sleep, to have opportunities to socialize) and prioritized the construction of objective indicators within each dimension. ${ }^{5}$

\section{Evaluation methodology and data sources}

The objective of the evaluation is to measure the average effect of TECHO's emergency housing programme on the wellbeing of the households that participate in the programme, that is, the average treatment effect on the treated. The methodologies available for this evaluation were constrained by two conditions set by TECHO Argentina: first, to not alter the programme's implementation process and, second, to not delay the provision of the house to any potential beneficiary that satisfied the programme's requirements and for whom resources were available. These conditions ruled out the possibility of using either random assignment of households to treatment and control groups or the difference in difference methodology.

Given these constraints, we chose to use a quasi-experimental pipeline approach methodology. Pipeline comparisons exploit the variation in the time of treatment, using as the control group participants that have been selected for the programme but have not yet 
received treatment (Coleman, 1999; Bali Swain and Varghese, 2009; White and Barbu, 2006 and Deininger and Liu, 2013).

The evaluation is based on information collected through two survey questionnaires: a baseline survey applied to households (both treatment and control) after being selected for the programme but before receiving the house and a follow-up survey applied to the treated households approximately one year after receiving the dwelling. ${ }^{7}$ The baseline survey collected information on the sociodemographic characteristics of the household; household income; the size, quality and use of the house; health; sleep; psychological wellbeing; security; socialization and perception of wellbeing. The followup survey began by identifying the members that were added to or left the household during the previous year and collected demographic data only on the new members and then maintained the basic structure of the baseline survey. Both surveys also collected, through the use of a sketch, detailed information on the layout and use of each room and the location, size and occupants of each bed. When the treated household used another dwelling in addition to the TECHO house, the follow-up survey collected information on both dwellings.

The treatment group is comprised of the households that received the TECHO house during the first half of 2014. A total of 334 households were included in the treatment group baseline survey, whereas the follow-up survey was applied to the 293 households that were still living in the neighbourhood at the time of the survey. Section six presents an analysis of the sensitivity of the results to the attrition of 41 households. The control group is comprised of the 352 households that received the TECHO house during the first half of 2015.

The cases were drawn from 34 informal settlements in Greater Buenos Aires in which TECHO carried out its programme in 2014 and $2015 .{ }^{8}$ The number of households 
living in each settlement ranged from 40 to 3000. All of the settlements have a severe deficit in basic public services. Less than half have access to the public water system (with irregular connections in all but 3 cases) and cesspit is the most common form of sewage disposal. Two thirds of the neighbourhoods have no paved roads and in another six only the main road is paved.

Since both the treatment and control groups passed through the same selection process they should be highly similar. Table 1 presents summary statistics on 17 pretreatment characteristics. The results of tests of comparison of means indicate that there is not a statistically significant difference between the treatment and control groups for any of the variables considered. Moreover, the low value of the normalized difference $-\mathrm{a}$ 'scale and sample size free' measure for assessing differences between treatment and control covariates (Imbens, 2015: 383) — for all of the variables indicates that regression analysis is a valid method for estimating the effects of treatment. ${ }^{9}$

It is relevant to consider, however, potential sources of selection bias. First, there could be systematic differences in the level of need of the households treated in one year compared with another. In order to ensure similarity in the initial conditions of the two groups, an effort was made to select control and treatment households from the same or adjacent neighbourhoods. Also, the fact that the organization does not tend to probe each neighbourhood selecting first the most vulnerable households, but rather tends to divide the neighbourhoods in sections, working first in one section and then in another, makes it less likely for the households selected in one year to be necessarily more or less vulnerable than those selected in the following year. If there were a tendency to offer the programme first to the neediest households, this would cause the control group to be relatively less vulnerable, biasing downward the impact estimates. 
A second possible source of selection bias could be differences in households' behavioural responses. This could occur, for example, if the growing awareness of the programme in the neighbourhood caused more and more families to ask to be considered for the programme. However, while any household can ask to be included in the detection survey, only those classified as high or medium-high need are eligible to participate.

It is also important to consider the potential problems of contamination due to possible spillover effects on the control group. While control households could benefit indirectly from the programme - for example, if they have the opportunity to visit and spend time in their neighbours' new houses - one would expect these indirect effects to be far smaller than the direct ones. The programme, moreover, could have motivated the control households to introduce their own housing improvements (in an effort to 'keep up with the Joneses') prior to receiving treatment, biasing downwards the impact estimates. The participants should not, however, have had an incentive to invest less in their houses so as to increase the chance of being selected, since at the time of the baseline survey both the treatment and control group households already knew they had been selected for treatment.

The treatment effect, $\delta$, is estimated using the following regression equation:

$$
Y_{i}=\alpha+\boldsymbol{\beta} X_{i}+\gamma Z_{i}+\delta T_{i}+\varepsilon_{i}
$$

where $Y_{i}$ is the outcome of interest, $T_{i}$ is an indicator of treatment, $X_{i}$ is a set of observed household characteristics, $Z_{i}$ is a set of dummy variables for neighbourhoods and $\varepsilon_{i}$ is an error term reflecting unobserved characteristics that also affect $Y_{i}$. The control variables, $X_{i}$, include the 17 variables presented in Table 1 (all of which are based on pre-treatment data for both the control and treatment groups). Robust standard errors with neighbourhood clustering are used for the regression models (Abadie et al., 2017). 


\section{Results}

For each outcome indicator Table 2 presents the treatment group baseline mean and standard deviations, followed by the treatment group before-after difference, the control group baseline mean and standard deviation and the estimated treatment effect based on regression equation (1). P-values are in parenthesis. The treatment group before-after difference serves as a descriptive measure of what happened to the treated group after participating in the programme, although we cannot interpret this change as the causal effect of treatment.

For each impact indicator Table 2 also presents the results of two adjustment procedures used to correct for the increased likelihood of type I error (rejection of a true null hypothesis) when carrying out multiple hypothesis tests (Lehmann and Romano, 2005). Each test is applied to the family of indicators within each dimension. The Bonferroni adjustment rejects any hypothesis with $\mathrm{p}$-value $\leq \alpha / s$, where $s$ is the number of outcome variables in the dimension. Since there are substantive objections to the Bonferroni procedure, as it may increase too much the likelihood of type II errors (Perneger, 1998), we also present the results of the Holm stepwise procedure. ${ }^{10}$

The programme produced a large and statistically significant effect on all of the indicators related to dwelling size. The size of the dwelling increased from a control group baseline of $29 \mathrm{~m}^{2}$ to $37 \mathrm{~m}^{2}$, an average increase of nearly two meters per person. The average number of rooms increased from 2 to 2.6 rooms. There was also a statistically significant reduction in all three measures of overcrowding: the percentage of households with less than $5 \mathrm{~m}^{2}$ per person declined from 48 to 23 per cent, the percentage with overcrowding ( $>2$ persons per room) declined from 65 to 43 per cent and the percentage with critical overcrowding (>3 persons per room) increased from 37 to 13 per cent. 
The programme did not produce a statistically significant change in household size, suggesting that programme effects do not tend to be diluted by the incorporation of new members. While a substantial share of households experienced changes in composition between the baseline and follow-up surveys, most of the rotation was associated with common demographic changes, including births of children and grandchildren, young adults that left home and changes in partners. This result is in line with the findings of other studies which have found that housing improvements either reduce or keep constant household size (see Galiani and Schargrodsky, 2015, on the effects of land titling).

The results of the measurement of impact on housing quality indicate that the programme did not produce a substantial improvement in the share of rooms with a roof or walls made of materials classified as good quality. ${ }^{11}$ When evaluating this result it is relevant to note that the baseline survey showed that a high percentage of participating households already had housing components that were in theory appropriate, even though the deteriorated quality of the materials and the lack of insulation or finishing meant that they did not provide adequate protection (for example, uninsulated tin roofs and walls made of low quality, discarded wood).

The TECHO house, however, did produce a large and statistically significant effect on the shares of rooms with problems in the roof, walls and floor. The share of rooms with problems with the roof fell from a control group baseline of 75 to 38 per cent, the share with problems with the walls fell from 73 to 39 per cent and the share with a dirt floor or filtrations of water or dirt in the floor fell from 38 to 24 per cent. Moreover, the share of rooms that flood when it rains dropped from a control group baseline of 46 to 22 per cent. The effect on reducing flooding is particularly relevant given that around 60 per cent of the informal settlements in Argentina flood every time it rains heavily (TECHO, 2016). 
In the privacy dimension, the TECHO house produced a statistically significant reduction in all of the indicators and the size of the effects tends to be quite large. The percentage of households in which the members do not have space to dress in private fell from 40 to 25 per cent and the percentage in which members do not have space to be alone fell by more than half. Bed overcrowding also declined. The proportion of households in which at least one bed is overcrowded (has more than one person per bed space) declined from 71 to 56 per cent and the percentage in which all of the beds are overcrowded declined from 23 to 11 per cent. It is evident that the increase in the size of the dwelling permits households to add additional beds, thereby improving sleep privacy.

In the sleep dimension, the results show that the percentage of households in which at least one member has frequent problems falling asleep declines from 28 to 18 percent and the percentage in which at least one member wakes up frequently at night declines from 47 to 29 per cent. While there is no effect on the respondent's sleep duration, her sleep quality improves. The percentage of respondents that describe her sleep quality as bad or very bad falls from 31 to 20 per cent. Improvements in sleep quality could improve productivity and thus incomes, as there is evidence that sleep disturbances are associated with lower work productivity (Rosekind et al., 2010). It is important to note, however, that none of the sleep outcomes is statistically significant at the $10 \%$ level according to the pvalues adjusted for multiple hypothesis testing using the Bonferroni and the Holm procedures.

In health the majority of the treatment coefficients for the indicators of the prevalence of illness are negative. The only indicator, however, for which the effect is statistically significant is the percentage of households in which at least one member had highly frequent cough or congestion during the past year, for which the percentage drops from 37 to 25 per cent. 
The programme also produced a large and statistically significant reduction in all of the measures of insecurity. ${ }^{12}$ For example, the percentage of respondents concerned the dwelling could collapse declines from 37 to 11 per cent, the percentage concerned the house could be occupied declines from 35 to 26 per cent and the percentage that feel very or quite secure in the dwelling increases from 47 to 90 per cent. Moreover, the proportion of households whose dwelling had been robbed during the past year fell from 21 to 11 per cent, a result which contrasts with a previous evaluation which found no effect on the incidence of robbery (Galiani et al., 2016).

The effects of the TECHO house on the indicators related to activities in the home are mixed. The programme has no statistically significant effect on the use of the house to participate in handicrafts or trade activities. However, the percentage of households with school age children that have a tranquil place to study increases from 64 to 90 per cent. This result suggests that emergency housing programmes can not only improve current living conditions, but also may broaden children's opportunities in the long term, a finding that is consistent with other evidence on the impact of housing improvements on children's education (Goux and Maurin, 2005).

The program had a positive effect both on social relations within the household and with people from outside of the home. The percentage of households in which there is frequent conflict due to lack of space declined from 29 to only 3 per cent and the percentage of respondents that feel very or quite uncomfortable receiving visitors dropped from 29 to 4 per cent. Moreover, the responses to qualitative survey questions indicate that after receiving the TECHO house a preference for being alone, lack of relatives close by and conflict with relatives replaced 'lack of space' as the most important reason for not socializing. 
The program produced a substantial improvement in the psychological wellbeing of the respondent and in the perception of quality of life and satisfaction with housing. The percentage of respondents that reported having negative feelings (sadness, anxiety and depression) declined from 67 to 48 per cent, and the percentage that felt stress due to conflict in the home declined from 45 to 30 per cent. Finally, there was a large and statistically significant effect on the percentage of respondents that are very or quite satisfied with their quality of life, very or quite satisfied with their house, and that feel very or quite comfortable in their house.

In summary, the evidence indicates that TECHO's emergency housing programme has a large and statistically significant effect on privacy, security, interpersonal relations, psychological wellbeing, perception of quality of life and satisfaction with housing. The effect on activities in the dwelling is positive but of less magnitude and limited to only some of the indicators. In health the programme only produced a reduction in the prevalence of cough and congestion. Indicators of sleep quality improve, but the effects are not statistically significant after applying the adjustments for multiple hypothesis testing.

\section{Robustness tests}

In this section we analyse the robustness of the results. First, we consider the possible biases that could be caused by the following factors: non-random attrition, neighbourhood differences and seasonal differences in the time of the survey. Second, we estimate programme effects using the propensity score matching procedure. Third, we perform a falsification test in which we replace the treatment group post-treatment outcomes with the values from the baseline survey. All results are presented in Appendix Table 1.

\section{Tests for possible sources of bias}


Of the 334 households that received the treatment we were unable to resurvey a total of 41 households, implying an attrition rate of $12 \%$. Eighteen of the families lost to attrition sold the TECHO house, twenty families moved from the neighbourhood taking the house with them and three houses burned down. ${ }^{14}$

The attrition does not seem to be completely random as the attriters are more likely to have a complete nuclear family and a pregnant woman. To test the sensitivity of the results to this problem we employed a methodology in the spirit of work by Manski (see Tamer, 2010). We reran the pipeline regression model, imputing for the lost cases the highest and lowest values of the outcome variables (no imputation was required for the covariates as they are based on the baseline surveys). The focus here is on obtaining upper and lower bounds for the potential treatment effect. Note that when the effect is negative the upper bound indicates the smallest effect consistent with the sample. ${ }^{15}$

Examination of the results shows that most of the findings survive this test. All of the effects are qualitatively maintained in the interpersonal relations dimension; the majority of the results survive in dwelling size (6 out of 7), dwelling quality (4 out of 5), privacy (3 out of 5), security (3 out of 5) and psychological wellbeing and perception of quality of life (3 out of 5); none survive in sleep, health or activities in the dwelling. It is important to note, however, that this is arguably the most conservative approach to testing for attrition bias and, therefore, even if the effect does not survive the test, this may be due to the extreme assumptions made in defining the lower and upper bounds.

The variation in the neighbourhoods from which the treatment and control households were drawn is another possible source of bias. Only 17 neighbourhoods provided both treatment and control cases, 5 provided only treatment cases and 12 only control cases. To test for the possible effect of neighbourhood differences we re-estimated the pipeline regression including only the households from the 17 neighbourhoods from 
which both treatment and control cases were drawn. Considering the enormous loss in statistical power, it is notable that none of the variables loses statistical significance. ${ }^{16}$

Another concern is that some outcomes might depend on the season in which the survey was carried out due to the fact that, for example, respiratory problems are more common in winter and diarrhoea in the summer. There could also be seasonal differences in the respondent's mood. As the treatment and control group surveys were conducted in approximately the same range of months, we do not expect this to be a serious concern, but to check this formally we added dummy variables to control for summer, autumn and spring (base winter). Although these dummy variables are jointly significant in 16 of our regressions, the impact estimates in nearly all cases do not change. ${ }^{17}$

\section{Propensity score matching}

As a robustness test, following Rosenbaum and Rubin (1983), we used the propensity score matching (PSM) procedure to estimate the counterfactual based on a matched group of control households that are observationally most similar to those in the treatment group. To apply the three-step procedure we, first, estimated the probability of participation in treatment conditional on the 17 variables presented in Table 1. Second, we used the estimated model to calculate the propensity score for each observation. Third, nearest neighbour matching with replacement was used to identify for each treated household the control household with the closest propensity score. Impact was measured as: $D_{P S M}=$ $\frac{1}{N_{T}}\left[\sum_{i \in T} Y_{i}^{T}-\sum_{j \in C} w(i, j) Y_{j}^{C}\right]$ where $\mathrm{N}_{\mathrm{T}}$ is the number of treated households $\mathrm{i}$ and $\mathrm{w}(\mathrm{i}, \mathrm{j})$ is the weight used to aggregate outcomes for the matched control households $\mathrm{j}$. We employed the standard errors proposed by Abadie and Imbens (2012).

The majority of the results based on the PSM procedure are similar to those based on the pipeline regression, both in terms of the magnitude and the statistical significance of the treatment effects. The only exceptions are within the sleep, health and security 
dimensions. Whereas for the pipeline regression the treatment effects in sleep were not statistically significant, after applying the adjustments for multiple hypothesis testing, according to the PSM procedure the TECHO programme has a statistically significant effect on reducing the prevalence of sleep disturbances and the perception of poor sleep quality. In health based on PSM, the effect on reducing cough and congestion is not statistically significant after adjusting for multiple hypothesis testing, while the reduction in the percentage of households with at least one member who had joint pain during the past year is now statistically significant. In the security dimension, the treatment effects on the percentage of occupants that are concerned the house could be occupied and the prevalence of robbery lose statistical significance.

\section{Falsification test}

Lastly, we apply a falsification test in which we replace the treatment group post-treatment outcomes with the values from the baseline survey. If the estimated effects were only due to chance then the results of the falsification test model should be similar to the results of our original pipeline regression. The comparison of the estimates in the first and last columns of Appendix Table 1 shows that after adjusting for multiple hypothesis testing, the treatment effect disappears for all of the indicators for which we had found a statistically significant effect. ${ }^{18}$

\section{Conclusions}

This paper has sought to broaden the evidence on the effects on wellbeing of providing emergency housing on-site in urban slums. Working within the constraints set by TECHO Argentina - to not alter their programme's processes for the purpose of the evaluation and not delay the provision of housing to households that satisfied the eligibility criteria and for whom resources were available — we employ a quasi-experimental pipeline approach methodology using as the control group participants that had been selected for 
the programme but had not yet received treatment The fact that both treatment and control households passed through the same selection process and have highly similar observable characteristics suggests that the two groups on average are highly comparable. The results also hold up to numerous robustness tests. The pipeline approach may be particularly useful for measuring impact in informal settlements where high population density and data collection challenges can make random assignment or delaying treatment to some households more difficult.

The paper makes two main contributions to the literature. First, it shows that TECHO's emergency housing programme has a large effect on increasing the size and quality of housing. The percentage of families that experience critical overcrowding, for example, drops from 37 to below 13 per cent. There is also a marked reduction in the share of rooms with problems in their housing components (floor, walls and roof) and the share of rooms that flood when it rains declines by more than half.

Second, the evidence indicates that the programme has a large and statistically significant effect on privacy, security, interpersonal relations, psychological wellbeing and perception of quality of life. In health the program produces a reduction in the prevalence of cough and congestion. Indicators of sleep quality improve, but the effects are not statistically significant after adjusting for multiple hypothesis testing. The programme also increases the percentage of families with school age children that have a tranquil place to study, evidence that the TECHO programme could broaden children's long-term opportunities.

The limitations of emergency housing interventions, however, are also evident. One out of four households that participated in the programme still does not have sufficient space to dress in private, more than half have over-crowded beds, four in ten households with children do not have a tranquil place to study and in one in four households the 
respondent is concerned that the house could be occupied. Moreover, while the evaluation shows a marked improvement in living conditions one year after receiving treatment, as the dwelling was designed to provide only temporary shelter, we cannot make any conclusions about how long these improvements in living conditions will last. The findings therefore also point to the urgent need to introduce public policies to broaden access to affordable housing; extend water, sanitation and other public services; formalize land tenancy and take other actions to contribute to expanding the capabilities of the people living in urban slums. 


\section{Endnotes}

1 The informal settlements included in this study satisfy the operational definition employed by TECHO: neighbourhoods with at least eight families in which at least half of the households do not have a formal land title nor formal access to at least two basic services (water, sanitation and electricity) (TECHO, 2013).

${ }^{2}$ While all of the households that were selected for the program chose to participate, a few households did not receive the dwelling due to lack of compliance with the contract's conditions.

${ }^{3}$ Poverty estimates are based on the poverty and indigence lines set by Salvia (2014:40).

${ }^{4}$ Some studies have shown positive effects of density on wellbeing. Regoeczi (2002), however, demonstrated that the apparent inconsistency in the literature is due to threshold effects. While negative behaviour may initially diminish with reductions in available space, once a critical threshold is reached, these problems increase exponentially with density.

5 The decision to prioritize objective indicators was motivated by the evidence that prolonged periods of deprivation can distort perceptions of wellbeing-what Sen (1985) refers to as 'adaptive preferences' - and that people tend to compare their living conditions with those of people living within their geographic or social proximity, rather than with society as a whole (Cruces et al., 2013). Another argument for focusing on objective over subjective indicators was to minimize the potential problem of confirmation or 'social desirability' bias (Kahneman, 2011) stemming from the participation of TECHO volunteers in the survey field work.

${ }^{6}$ A total of 20 households were divided during the year after receiving the TECHO house. In these cases, we applied the follow-up survey separately to each household in order to collect accurate information on all members but measured the combined effect on both households taken together. Section six presents tests of the sensitivity of the results to the exclusion of these 20 households.

${ }^{7}$ The respondent was the person who was considered to spend the most time in the home and was best able to provide information on all members. In most cases the respondent was the mother of the principal nuclear family.

${ }^{8}$ Due to the continuous expansion of Greater Buenos Aires, all of the settlements included in the survey form part of the same urban area that extends from Pilar in the north to La Matanza in the west and Greater La Plata in the south.

${ }^{9}$ The normalized difference is defined as: $\frac{\left(\bar{X}_{T}-\bar{X}_{C}\right)}{\sqrt{\left(S_{X, T}^{2}+S_{X, C}^{2}\right) / 2}}$, where $\bar{X}_{T}$ and $\bar{X}_{C}$ are, respectively, the treatment and control group means and $S_{X, T}^{2}$ and $S_{X, C}^{2}$ the treatment and control group variances of the covariates. Imbens and Wooldridge (2009) indicate that when the values of the normalized differences are greater than 0.25 - two and a half times greater than the highest value for any of our indicators - then one should be cautious about measuring treatment effects using a linear regression with a dummy variable for treatment.

${ }^{10}$ To apply the Holm procedure one, first, orders the family of p-values i from smallest to largest and then sequentially rejects each hypothesis as long as p-value $<\alpha_{i}=\alpha /(s-$ $i+1)$.

${ }^{11}$ In order to obtain a unit of analysis that would permit comparisons across households that use the TECHO house in different ways, each dummy variable describing the quality of the dwelling was used to construct a new indicator referring to the fraction of rooms with each characteristic.

12 All security indicators refer to the security of the TECHO house, except for the respondent's perception of security which refers to the dwelling in which the respondent sleeps and robbery which refers to robbery in either the TECHO house or other dwellings. 
${ }^{14}$ Fires are common in the settlements and there is no evidence that the incidence of fires is higher among programme participants than in the overall population in the settlements.

${ }^{15}$ When both the higher and lower bound coefficient estimates are statistically significant and the same sign there is no way that the 'lost' cases could have changed the results enough for the true effect to be zero. If the two regressions have different signs, they include the zero in the interval, and it is possible for the true effect to be zero. If the two regressions have the same sign, but only one is statistically significant, one of the bounds includes the zero in its confidence interval and thus we cannot be sure that attrition did not lead us to conclude there was an effect when there really was none.

${ }^{16}$ As the distribution of the number of treatment and control households drawn from each neighbourhood showed that there was a negative correlation in the quantity of households surveyed in each neighbourhood between the two periods we also applied the following test. We obtained two additional sets of impact estimates: one in which we included only those neighbourhoods with more treatment than control households and another with the neighbourhoods with more control than treatment households. A comparison of the results, however, did not show any clear pattern. For some variables the coefficient increases and for others the coefficient declines, suggesting that the sequential process of selecting treatment and control households did not lead to the selection of relatively more (or less) needy households for the control group.

${ }^{17}$ Additionally, in order to assess how changes in the respondent (16 cases) and the division of households ( 20 cases) between the baseline and follow-up surveys could be affecting our results, we re-estimated the pipeline regression model excluding these 36 cases. As a result of this change, the effects were virtually unaltered in terms of economic or statistical significance.

${ }^{18}$ In a final robustness test we re-estimated the pipeline regression using contemporaneous instead of pre-treatment values for the control variables. The results show that using contemporaneous controls causes seven outcome variables that were previously not statistically significant to become significant, whereas none of the outcome variables loses statistical significance, suggesting that the use of pre-treatment values for the control variables clearly does not result in the overestimation of impact. 


\section{References}

Abadie, A. Athey, S. Imbens, G. and Wooldridge, J. (2017) When Should You Adjust Standard Errors for Clustering. Retrieved from https://arxiv.org/abs/1710.02926.

Abadie, A., and Imbens, G. W. (2012) Matching on the Estimated Propensity Score Econometrica, 84(2): 781-807.

Benicio, D’A. M.H., Ferreira, M.U., Cardoso, M.R., Konno, S.C. and Monteiro, C.A. (2004) Wheezing conditions in early childhood: Prevalence and risk factors in San Paolo, Brazil. Bulletin of the World Health Organization, 82: 51-522.

Bonnefoy, X. (2007) Inadequate housing and health: an overview. Int. J. Environment and Pollution, 30(3): 411-429.

Bouillon, C. P. (ed.) (2012) Un espacio para el desarrollo: Los mercados de vivienda en América Latina y el Caribe. Washington, DC: Inter-American Development Bank.

Cardinali, D. P., Espinola, G.S.S.R., Salvia, A. and Vigo, D.P.C.D.E. (2014) Sleep, Slums and Shelter: Impact of a Slum-housing Upgrading Programme. In: Bread and Brain, Education and Poverty. Vatican City: Pontifical Academy of Sciences, pp. 1-14.

Cattaneo, M.D., Galiani, S., Gertler, P.J., Martinez, S. and Titiunik, R. (2009) Housing, Health and Happiness. American Economic Journal: Economic Policy, 1(1): 75-105.

Coleman, B. (1999) The Impact of Lending in Northeastern Thailand. Journal of Development Economics, 60: 105-141.

Cruces, G., Pérez Truglia, R. and Tetaz, M. (2013) Biased perceptions of income distribution and preferences for redistribution: Evidence from a survey experiment. Journal of Public Economics, 98(C): 100-112.

Deininger, K., and Liu, Y. (2013) Economic and Social Impacts of an Innovative Self-Help Group Model in India. World Development, 43: 149-163.

Devoto, F., Duflo, E., Dupas, P., Parienté, W. and Pons, V. (2012) Happiness on tap: Piped water adoption in urban Morocco. American Economic Journal: Economic Policy, 4(4): 68-99.

Evans, G. W., Lepore, S. J., Shejwal, B. R. and Palsane, M. N. (1998). Chronic Residential Crowding and Children's Well-Being: An Ecological Perspective. Child Development, 69(6): 1514-1523.

Evans, G. W., Wells, N.M., Chan, E. and Saltzman, H. (2000) Housing and mental health. Journal of Consulting and Clinical Psychology, 68: 526-530.

Field, E. (2004) Property Rights, Community Public Goods, and Household Time Allocation in Urban Squatter Communities: Evidence from Peru. William and Mary Law Review, 45: 837-887.

Fonseca W., Kirkwood B.R., Victora C.G., Fuchs S.R., Flores J.A. and Misago C. (1996) Risk factors for childhood pneumonia among the urban poor in Fortaleza, Brazil: a casecontrol study. Bulletin World Health Organization, 74(2): 199-208.

Galiani, S., Gertler, P., Undurraga, R., Cooper, R., Martinez, S. and Ross, A. (2016) Shelter from the Storm: Upgrading housing infrastructure in Latin American slums. Journal of Urban Economics, 96:166-194. 
Galiani, S. and Schargrodsky, E. (2010) Property rights for the poor: Effects of land titling. Journal of Public Economics, 94: 700-729.

Goux, D., and Maurin, E. (2005) The effect of overcrowded housing on children's performance at school. Journal of Public Economics, 89(5): 797-819.

Gove, W. R., Hughes, M., and Galle, O. R. (1979) Overcrowding in the home: An empirical investigation of its possible pathological consequences. American Sociological Review, 44(1): 59-80.

Imbens, G. W. (2015) Matching Methods in Practice: Three Examples. Journal of Human Resources, 50(2): 373-419.

Imbens, G. W. and Wooldridge, J. M. (2009). Recent Developments in the Econometrics of Program Evaluation. Journal of Economic Literature, 47(1): 5-86.

Jaitman, L. and Brakarz, J. (2013) Evaluation of Slum Upgrading Programmes. Literature Review and Methodological Approaches. IDB-TN-604, Washington, DC: Inter-American Development Bank.

Kahneman, D. (2011) Thinking, fast and slow. London: Allen Lane.

Lehmann, E.L. and Romano, J. (2005) Testing Statistical Hypotheses. New York: Springer.

Murtagh P., Cerqueiro C., Halac A., Avila M., Salomon H. and Weissenbacher M. (1993) Acute lower respiratory infection in Argentinian children: a 40 month clinical and epidemiological study. Pediatric Pulmonology, 16(1): 1-8.

Newman, S. J. (2008) Does housing matter for poor families? A critical summary of research and issues still to be resolved Journal of Policy Analysis and Management, 27(4): 895-925.

Ortiz Flores, E. (2011) La Producción Social del Hábitat. In: Arébalo, M et al. El Camino Posible. Producción social de hábitat en América Latina. Montevideo: Ediciones Trilce.

Peat J.K., Dickerson J. and Li, J. (1998) Effects of damp and mold in the home on respiratory health: a review of the literature. Allergy, 53: 120-128.

Perneger, T. V. (1998) What's wrong with Bonferroni adjustments. British Medical Journal, 316: 1236-1238.

Regoeczi, W. (2002) The Impact of Density: The Importance of Nonlinearity and Selection on Flight and Fight Responses. Social Forces, 81(2): 505-530.

Rojas, E. and Medellin, N. (2011) Housing Policy Matters for the Poor Housing Conditions in Latin America and the Caribbean, 1995-2006. IDB Working Paper Series No. 289. Washington, DC: Inter-American Development Bank.

Rosekind, M. R., Gregory, K, B., Mallis, M. M., Brandt, S., Seal, B. and Lerner, D. (2010) The Cost of Poor Sleep: Workplace Productivity Loss and Associated Costs. Journal of Occupational and Environmental Medicine, 52(1): 91-98.

Rosenbaum, P.R. and Rubin, D.B. (1983) The Central Role of the Propensity Score in Observational Studies for Causal Effects Biometrica, 70(1): 41-55.

Salvia, A. (ed.) (2014) Un régimen consolidado de bienestar con desigualdades sociales persistentes, claroscuros en el desarrollo humano y la integración social 2010-2013. 1st ed. Buenos Aires: Educa. 
Sen, A. (1985) Well-Being, Agency and Freedom: The Dewey Lectures 1984. The Journal of Philosophy, 82(4): 169-221.

Sen, A. (1999) Development as Freedom, Oxford: Oxford University Press.

Simonelli, G., Leanza, Y., Boilard, A., Hyland, M., Augustinavicius, J. L., Cardinali, D. P. and Vigo, D. E. (2013) Sleep and Quality of Life in Urban Poverty: The Effect of a Slum Housing Upgrading Programme. Sleep, 36(11): 1669-1676.

Simonelli, G. Patel, S., Rodríguez-Espínola, S., Pérez-Chada, D., Salvia, A., Cardinali, D. and Vigo, D. (2015) The impact of home safety on sleep in a Latin American country Sleep Health, 1(2): 98-103.

Solari, C. D., and Mare, R. D. (2011). Housing crowding effects on children's wellbeing. Social Science Research, 41(2): 464-476.

Bali Swain, R., and Varghese, A. (2009) Does Self Help Group Participation Lead to Asset Creation? World Development, 37.10: 1674-1682.

Tamer, E. (2010) Partial identification in econometrics. Annual Review of Economics 2(1): 167-195.

TECHO Argentina (2013) Relevamiento de Asentamientos Informales 2013. Retrieved April 10, 2016 from:

https://issuu.com/techoargentina/docs/relevamientos_de_asentamientos_2013

TECHO Argentina (2016) Relevamiento de Asentamientos Informales 2016. Retrieved January 15, 2017 from: http://www.techo.org/paises/argentina/que-es-el-centro-deinvestigacion-social-cis/www.techo.org.ar/relevamiento

Thomson, H., Thomas, S., Sellstrom, E. and Petticrew, M. (2009) The Health Impacts of Housing Improvement: A Systematic Review of Intervention Studies From 1887 to 2007. American Journal of Public Health 99(Suppl. 3): S681-S692.

UN-Habitat (2016) World Cities Report 2016. Nairobi: United Nations Human Settlements Programme.

White, H. and Barbu, A. (2006) Impact evaluation - the experience of the independent evaluation group of the World Bank. Washington, DC: World Bank. 
Figure 1: TECHO Argentina's emergency house

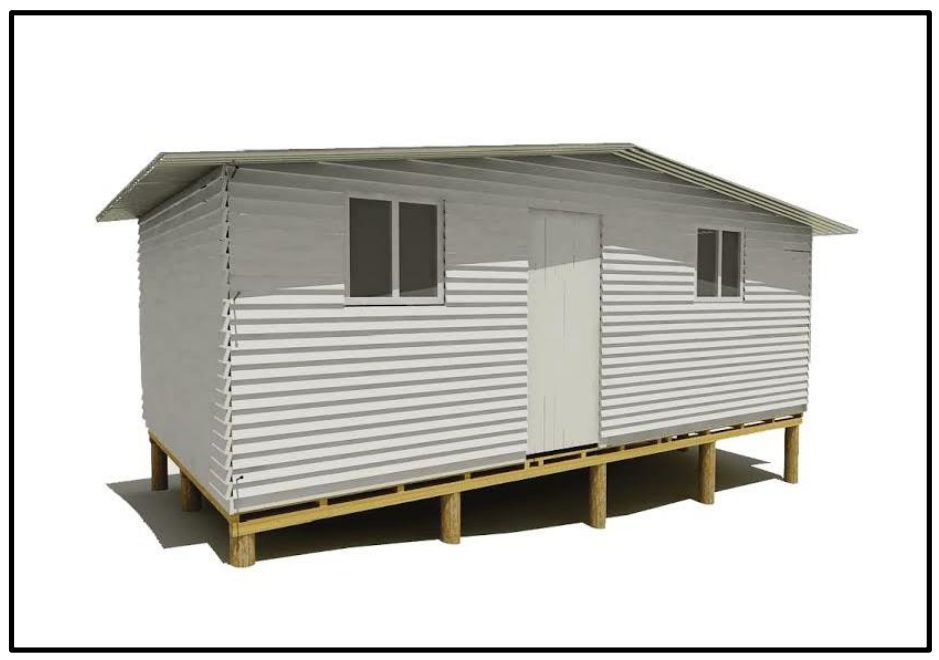

Source: TECHO Argentina. 
Table 1. Pre-treatment characteristics of the treatment and control groups

\begin{tabular}{|c|c|c|c|c|c|c|}
\hline \multirow[b]{2}{*}{ Characteristics } & \multicolumn{2}{|c|}{ Control } & \multicolumn{2}{|c|}{ Treatment } & \multirow[b]{2}{*}{ t-stat } & \multirow{2}{*}{$\begin{array}{c}\text { Normalized } \\
\text { difference }\end{array}$} \\
\hline & Mean & $\begin{array}{l}\text { Stnd. } \\
\text { Dev. }\end{array}$ & Mean & $\begin{array}{l}\text { Stnd. } \\
\text { Dev. }\end{array}$ & & \\
\hline Number of nuclear family units & 1.38 & 0.60 & 1.37 & 0.61 & 0.25 & -0.020 \\
\hline Respondent and spouse in household & 0.75 & 0.44 & 0.70 & 0.46 & 1.34 & -0.106 \\
\hline Share of members under age 5 & 0.27 & 0.19 & 0.26 & 0.19 & 0.14 & -0.011 \\
\hline Share of members ages 6 to 17 & 0.24 & 0.21 & 0.26 & 0.21 & -1.11 & 0.088 \\
\hline Pregnant woman in household & 0.14 & 0.34 & 0.15 & 0.35 & -0.36 & 0.029 \\
\hline Respondent's age & 32.99 & 12.47 & 34.26 & 13.22 & -1.25 & 0.099 \\
\hline Respondent is male & 0.17 & 0.38 & 0.16 & 0.37 & 0.22 & -0.018 \\
\hline Respondent is a foreigner & 0.04 & 0.20 & 0.06 & 0.23 & -0.88 & 0.070 \\
\hline Respondent is from another province & 0.19 & 0.40 & 0.19 & 0.39 & 0.07 & -0.005 \\
\hline Respondent completed only primary school & 0.22 & 0.41 & 0.26 & 0.44 & -1.10 & 0.087 \\
\hline Respondent has some secondary school & 0.37 & 0.48 & 0.36 & 0.48 & 0.12 & -0.010 \\
\hline Respondent completed secondary school & 0.13 & 0.34 & 0.11 & 0.32 & 0.70 & -0.055 \\
\hline Respondent works & 0.44 & 0.50 & 0.47 & 0.50 & -0.62 & 0.049 \\
\hline Respondent's spouse works & 0.63 & 0.48 & 0.59 & 0.49 & 1.06 & -0.084 \\
\hline Number of other family members who work & 0.50 & 0.89 & 0.49 & 0.84 & 0.22 & -0.017 \\
\hline Income per capita (4th-Quarter 2014 pesos) & 1,000 & 700 & 1,019 & 873 & -0.31 & 0.025 \\
\hline At least one member has asthma & 0.22 & 0.42 & 0.22 & 0.42 & -0.01 & 0.001 \\
\hline
\end{tabular}


Table 2. Effect of the TECHO house on outcome indicators

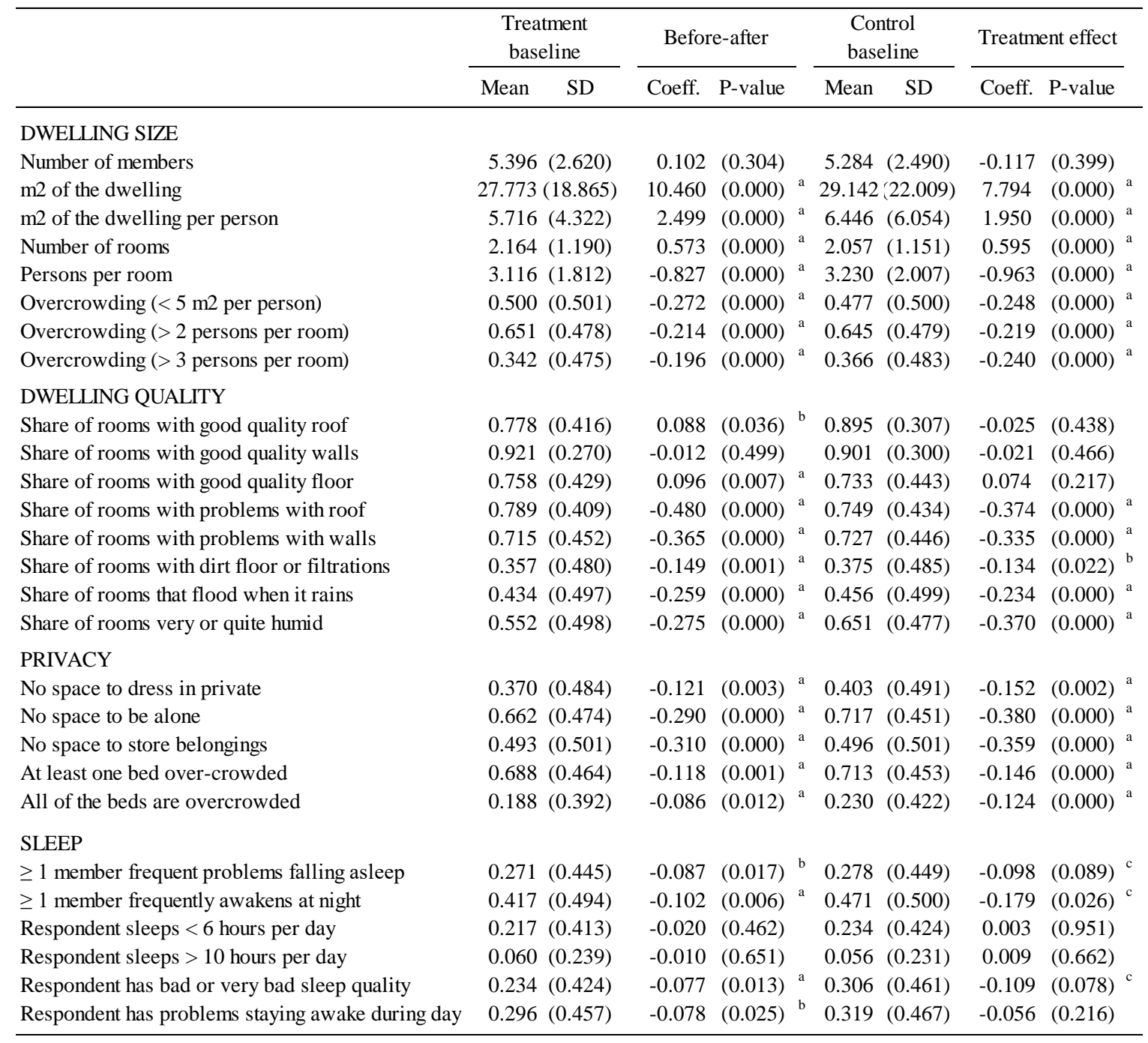


Table 2. Effect of the TECHO house on outcome indicators (cont.)

\begin{tabular}{|c|c|c|c|c|c|c|c|c|c|c|}
\hline & \multicolumn{2}{|c|}{$\begin{array}{c}\text { Treatment } \\
\text { baseline }\end{array}$} & \multicolumn{3}{|c|}{ Before-after } & \multicolumn{2}{|c|}{$\begin{array}{r}\text { Control } \\
\text { baseline }\end{array}$} & \multicolumn{3}{|c|}{ Treatment effect } \\
\hline & Mean & SD & Coeff. & P-value & & Mean & SD & Coeff. & P-value & \\
\hline \multicolumn{11}{|l|}{ HEALTH } \\
\hline$\geq 1$ member had frequent cough/congestion past year & 0.306 & $(0.462)$ & -0.060 & $(0.114)$ & & 0.371 & $(0.484)$ & -0.118 & $(0.007)$ & \\
\hline$\geq 1$ member had bronchitis/pneumonia past year & 0.401 & $(0.491)$ & -0.021 & $(0.355)$ & & 0.454 & $(0.499)$ & -0.043 & $(0.333)$ & \\
\hline$\geq 1$ member had highly frequent joint pain past year & 0.266 & $(0.443)$ & -0.010 & $(0.722)$ & & 0.334 & $(0.472)$ & -0.058 & $(0.301)$ & \\
\hline$<$ age 6 with diarrhoea during past month & 0.274 & $(0.448)$ & 0.040 & $(0.528)$ & & 0.250 & $(0.434)$ & 0.018 & $(0.790)$ & \\
\hline Respondent satisfied with health & 0.786 & $(0.411)$ & 0.028 & $(0.437)$ & & 0.783 & $(0.413)$ & 0.025 & $(0.678)$ & \\
\hline \multicolumn{11}{|l|}{ SECURITY } \\
\hline Respondent worried about condition of dwelling & 0.618 & $(0.487)$ & -0.509 & $(0.000)$ & & 0.628 & $(0.484)$ & -0.447 & $(0.000)$ & \\
\hline Respondent concerned house could collapse & 0.362 & $(0.481)$ & -0.311 & $(0.000)$ & 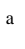 & 0.368 & $(0.483)$ & -0.258 & $(0.000)$ & \\
\hline House was robbed during the past year & 0.171 & $(0.377)$ & -0.061 & $(0.002)$ & a & 0.210 & $(0.408)$ & -0.095 & $(0.004)$ & \\
\hline Respondent concerned house could be occupied & 0.390 & $(0.489)$ & -0.133 & $(0.007)$ & a & 0.346 & $(0.476)$ & -0.091 & $(0.019)$ & \\
\hline Respondent feels secure in the dwelling & 0.488 & $(0.501)$ & 0.430 & $(0.000)$ & a & 0.474 & $(0.500)$ & 0.428 & $(0.000)$ & \\
\hline \multicolumn{11}{|l|}{ ACTIVITIES IN THE DWELLING } \\
\hline Trade or handicraft in the home & 0.392 & $(0.489)$ & -0.039 & $(0.363)$ & & 0.281 & $(0.450)$ & -0.004 & $(0.959)$ & \\
\hline Non-profit trade or handicraft in the home & 0.206 & $(0.405)$ & -0.064 & $(0.033)$ & & 0.102 & $(0.303)$ & 0.032 & $(0.387)$ & \\
\hline No tranquil place for children to study & 0.653 & $(0.479)$ & 0.245 & $(0.000)$ & a & 0.642 & $(0.480)$ & 0.259 & $(0.000)$ & \\
\hline \multicolumn{11}{|l|}{ INTERPERSONAL RELATIONS } \\
\hline Frequent conflict due to lack of space & 0.227 & $(0.420)$ & -0.165 & $(0.000)$ & & 0.289 & $(0.454)$ & -0.261 & $(0.000)$ & a \\
\hline Never receive friends in the home & 0.137 & $(0.345)$ & -0.049 & $(0.042)$ & & 0.128 & $(0.334)$ & -0.029 & $(0.283)$ & \\
\hline Respondent uncomfortable receiving friends & 0.286 & $(0.453)$ & -0.225 & $(0.000)$ & & 0.289 & $(0.454)$ & -0.254 & $(0.000)$ & a \\
\hline \multicolumn{11}{|c|}{ PSYCHOLOGICAL WELLBEING AND PERCEPTION OF WELLBEING } \\
\hline Respondent had negative feelings last month & 0.642 & $(0.480)$ & -0.136 & $(0.002)$ & & 0.665 & $(0.473)$ & -0.190 & $(0.003)$ & \\
\hline Respondent had negative feelings every day & 0.234 & $(0.424)$ & -0.061 & $(0.214)$ & & 0.228 & $(0.420)$ & -0.059 & $(0.411)$ & \\
\hline Respondent feels stress due to conflict in home & 0.453 & $(0.499)$ & -0.128 & $(0.000)$ & & 0.452 & $(0.498)$ & -0.147 & $(0.018)$ & b \\
\hline Respondent feels stress due to conflict every day & 0.160 & $(0.367)$ & -0.047 & $(0.190)$ & & 0.161 & $(0.368)$ & -0.049 & $(0.322)$ & \\
\hline Respondent has good quality of life & 0.813 & $(0.390)$ & 0.111 & $(0.002)$ & & 0.799 & $(0.401)$ & 0.116 & $(0.002)$ & \\
\hline Respondent is satisfied with house & 0.401 & $(0.491)$ & 0.589 & $(0.000)$ & a & 0.450 & $(0.498)$ & 0.532 & $(0.000)$ & \\
\hline Respondent is comfortable in the house & 0.441 & $(0.497)$ & 0.544 & $(0.000)$ & a & 0.393 & $(0.489)$ & 0.589 & $(0.000)$ & \\
\hline \multicolumn{11}{|c|}{$\begin{array}{l}\text { Notes: The table presents the treatment group baseline mean and standard deviation, followed by the treatment group before- } \\
\text { after difference, the control group baseline mean and standard deviation and the estimated treatement effect based on a } \\
\text { regression model including as controls the } 17 \text { variables presented in Table } 1 \text { as well as neighborhood dummies. Robust } \\
\text { standard errors with neighborhood clustering used for all regression models. }\end{array}$} \\
\hline \multicolumn{11}{|c|}{${ }^{\mathrm{a}}$ Treatment dummy is statistically significant at least at the $10 \%$ level according to the Bonferroni and the Holm tests. } \\
\hline 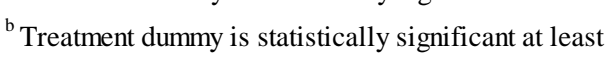 & 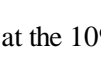 & (1) & & & & & & & & \\
\hline
\end{tabular}


Appendix Table 1. Robustness tests on the treatment effect of the TECHO house

\begin{tabular}{|c|c|c|c|c|c|c|c|c|c|c|c|c|c|c|}
\hline & \multirow{2}{*}{\multicolumn{2}{|c|}{$\begin{array}{c}\text { Original Regression } \\
\text { Model } \\
\end{array}$}} & \multicolumn{4}{|c|}{ Attrition Tests } & \multirow{2}{*}{\multicolumn{2}{|c|}{ Neighbourhood test }} & \multirow{2}{*}{\multicolumn{2}{|c|}{ Time of year }} & \multirow{2}{*}{\multicolumn{2}{|c|}{$\begin{array}{c}\text { Propensity score } \\
\text { matching }\end{array}$}} & \multirow{2}{*}{\multicolumn{2}{|c|}{ Falsification test }} \\
\hline & & & \multicolumn{2}{|c|}{ Upper bound } & \multicolumn{2}{|c|}{ Lower bound } & & & & & & & & \\
\hline & Coeff. & P-value & Coeff. & P-value & Coeff. & P-value & Coeff. & P-value & Coeff. & P-value & Coeff. & P-value & Coeff. & P-value \\
\hline \multicolumn{15}{|l|}{ DWELLING SIZE } \\
\hline Number of members & -0.117 & $(0.399)$ & 1.802 & $(0.000)$ & -0.797 & $(0.000)$ & -0.118 & $(0.454)$ & -0.203 & $(0.159)$ & 0.196 & $(0.315)$ & 0.052 & $(0.657)$ \\
\hline $\mathrm{m}^{2}$ of the dwelling & 7.794 & $(0.000)^{\mathrm{a}}$ & 28.370 & $(0.000)$ & 3.028 & $(0.146)$ & 8.073 & $(0.000)^{\mathrm{a}}$ & 7.350 & $(0.002)^{\mathrm{a}}$ & 8.448 & $(0.000)^{a}$ & -1.622 & $(0.492)$ \\
\hline $\mathrm{m}^{2}$ of the dwelling per person & 1.950 & $(0.000)^{\mathrm{a}}$ & 10.100 & $(0.000)$ & 1.056 & $(0.034)$ & 2.036 & $(0.001)^{\mathrm{a}}$ & 1.557 & $(0.003)^{a}$ & 1.956 & $(0.001)^{\mathrm{a}}$ & -0.754 & $(0.142)$ \\
\hline Number of rooms & 0.595 & $(0.000)^{\mathrm{a}}$ & 1.221 & $(0.000)$ & 0.354 & $(0.002)$ & 0.596 & $(0.000)^{\mathrm{a}}$ & 0.502 & $(0.000)^{\mathrm{a}}$ & 0.694 & $(0.000)^{\mathrm{a}}$ & 0.119 & $(0.394)$ \\
\hline Persons per room & -0.963 & $(0.000)^{\mathrm{a}}$ & 0.418 & $(0.155)$ & -1.267 & $(0.000)$ & -0.953 & $(0.000)^{\mathrm{a}}$ & -0.874 & $(0.000)^{\mathrm{a}}$ & -0.971 & $(0.000)^{\mathrm{a}}$ & -0.138 & $(0.473)$ \\
\hline Overcrowding $\left(<5 \mathrm{~m}^{2}\right.$ per person $)$ & -0.248 & $(0.000)^{\mathrm{a}}$ & -0.139 & $(0.016)$ & -0.283 & $(0.000)$ & -0.247 & $(0.000)^{\mathrm{a}}$ & -0.301 & $(0.000)^{\mathrm{a}}$ & -0.227 & $(0.000)^{\mathrm{a}}$ & 0.013 & $(0.735)$ \\
\hline Overcrowding ( $>2$ persons per room) & -0.219 & $(0.000)^{\mathrm{a}}$ & -0.145 & $(0.001)$ & -0.289 & $(0.000)$ & -0.221 & $(0.000)^{\mathrm{a}}$ & -0.201 & $(0.000)^{\mathrm{a}}$ & -0.203 & $(0.000)^{\mathrm{a}}$ & 0.003 & $(0.931)$ \\
\hline Overcrowding (> 3 persons per room) & -0.240 & $(0.000)^{\mathrm{a}}$ & -0.118 & $(0.008)$ & -0.262 & $(0.000)$ & -0.235 & $(0.000)^{\mathrm{a}}$ & -0.234 & $(0.000)^{\mathrm{a}}$ & -0.251 & $(0.000)^{\mathrm{a}}$ & -0.032 & $(0.499)$ \\
\hline \multicolumn{15}{|l|}{ DWELLING QUALITY } \\
\hline Share of rooms with good quality roof & -0.025 & $(0.438)$ & -0.005 & $(0.848)$ & -0.152 & $(0.000)$ & -0.027 & $(0.419)$ & -0.018 & $(0.583)$ & -0.005 & $(0.895)$ & -0.119 & $(0.026)^{\mathrm{c}}$ \\
\hline Share of rooms with good quality walls & -0.021 & $(0.466)$ & -0.005 & $(0.877)$ & -0.153 & $(0.000)$ & -0.021 & $(0.491)$ & -0.007 & $(0.786)$ & -0.040 & $(0.127)$ & 0.018 & $(0.538)$ \\
\hline Share of rooms with good quality floor & 0.074 & $(0.217)$ & 0.095 & $(0.111)$ & -0.052 & $(0.405)$ & 0.072 & $(0.247)$ & 0.090 & $(0.194)$ & 0.104 & $(0.022)^{b}$ & 0.026 & $(0.547)$ \\
\hline Share of rooms with problems with roof & -0.374 & $(0.000)^{\mathrm{a}}$ & -0.278 & $(0.000)$ & -0.425 & $(0.000)$ & -0.373 & $(0.000)^{\mathrm{a}}$ & -0.375 & $(0.000)^{\mathrm{a}}$ & -0.413 & $(0.000)^{\mathrm{a}}$ & 0.045 & $(0.218)$ \\
\hline Share of rooms with problems with walls & -0.335 & $(0.000)^{\mathrm{a}}$ & -0.246 & $(0.000)$ & -0.394 & $(0.000)$ & -0.334 & $(0.000)^{\mathrm{a}}$ & -0.319 & $(0.000)^{\mathrm{a}}$ & -0.287 & $(0.000)^{\mathrm{a}}$ & -0.002 & $(0.962)$ \\
\hline Share of rooms with dirt floor or filtrations & -0.134 & $(0.022)^{b}$ & -0.018 & $(0.759)$ & -0.163 & $(0.004)$ & -0.130 & $(0.037)^{\mathrm{c}}$ & -0.149 & $(0.050)^{\mathrm{c}}$ & -0.177 & $(0.000)^{\mathrm{a}}$ & -0.026 & $(0.572)$ \\
\hline Share of rooms that flood when it rains & -0.234 & $(0.000)^{\mathrm{a}}$ & -0.106 & $(0.092)$ & -0.254 & $(0.000)$ & -0.236 & $(0.001)^{\mathrm{a}}$ & -0.221 & $(0.000)^{\mathrm{a}}$ & -0.266 & $(0.000)^{\mathrm{a}}$ & -0.031 & $(0.481)$ \\
\hline Share of rooms very or quite humid & -0.370 & $(0.000)^{\mathrm{a}}$ & -0.269 & $(0.000)$ & -0.417 & $(0.000)$ & -0.375 & $(0.000)^{\mathrm{a}}$ & -0.390 & $(0.000)^{\mathrm{a}}$ & -0.340 & $(0.000)^{\mathrm{a}}$ & -0.095 & $(0.041)^{\mathrm{c}}$ \\
\hline \multicolumn{15}{|l|}{ PRIVACY } \\
\hline No space to dress in private & -0.152 & $(0.002)^{\mathrm{a}}$ & -0.053 & $(0.207)$ & -0.198 & $(0.000)$ & -0.150 & $(0.006)^{\mathrm{a}}$ & -0.180 & $(0.000)^{\mathrm{a}}$ & -0.135 & $(0.006)^{\mathrm{a}}$ & -0.035 & $(0.377)$ \\
\hline No space to be alone & -0.380 & $(0.000)^{\mathrm{a}}$ & -0.296 & $(0.000)$ & -0.440 & $(0.000)$ & -0.374 & $(0.000)^{\mathrm{a}}$ & -0.387 & $(0.000)^{\mathrm{a}}$ & -0.367 & $(0.000)^{\mathrm{a}}$ & -0.067 & $(0.088)^{c}$ \\
\hline No space to store belongings & -0.359 & $(0.000)^{\mathrm{a}}$ & -0.239 & $(0.000)$ & -0.386 & $(0.000)$ & -0.360 & $(0.000)^{\mathrm{a}}$ & -0.424 & $(0.000)^{\mathrm{a}}$ & -0.300 & $(0.000)^{\mathrm{a}}$ & -0.002 & $(0.965)$ \\
\hline At least one bed over-crowded & -0.146 & $(0.000)^{\mathrm{a}}$ & -0.082 & $(0.019)$ & -0.227 & $(0.000)$ & -0.151 & $(0.001)^{\mathrm{a}}$ & -0.169 & $(0.000)^{\mathrm{a}}$ & -0.179 & $(0.000)^{\mathrm{a}}$ & -0.025 & $(0.403)$ \\
\hline All of the beds are overcrowded & -0.124 & $(0.000)^{\mathrm{a}}$ & 0.001 & $(0.984)$ & -0.144 & $(0.000)$ & -0.129 & $(0.000)^{\mathrm{a}}$ & -0.121 & $(0.000)^{\mathrm{a}}$ & -0.079 & $(0.028)^{b}$ & -0.030 & $(0.293)$ \\
\hline \multicolumn{15}{|l|}{ SLEEP } \\
\hline$\geq 1$ member frequent problems falling asleep & -0.098 & $(0.089)^{\mathrm{c}}$ & 0.019 & $(0.763)$ & -0.126 & $(0.025)$ & -0.096 & $(0.105)$ & -0.086 & $(0.143)$ & -0.107 & $(0.019)^{\mathrm{b}}$ & -0.007 & $(0.840)$ \\
\hline$\geq 1$ member frequently awakens at night & -0.179 & $(0.026)^{c}$ & -0.082 & $(0.284)$ & -0.228 & $(0.003)$ & -0.181 & $(0.03)^{\mathrm{c}}$ & -0.175 & $(0.025)^{\mathrm{c}}$ & -0.125 & $(0.009)^{\mathrm{a}}$ & -0.056 & $(0.170)$ \\
\hline Respondent sleeps $<6$ hours per day & 0.003 & $(0.951)$ & 0.119 & $(0.018)$ & -0.025 & $(0.540)$ & 0.004 & $(0.935)$ & 0.017 & $(0.717)$ & -0.046 & $(0.244)$ & -0.028 & $(0.355)$ \\
\hline Respondent sleeps $>10$ hours per day & 0.009 & $(0.662)$ & 0.145 & $(0.000)$ & 0.001 & $(0.964)$ & 0.010 & $(0.644)$ & 0.011 & $(0.706)$ & 0.018 & $(0.418)$ & 0.015 & $(0.352)$ \\
\hline Respondent has bad or very bad sleep quality & -0.109 & $(0.078)^{\mathrm{c}}$ & 0.012 & $(0.841)$ & -0.134 & $(0.026)$ & -0.111 & $(0.080)^{\mathrm{c}}$ & -0.092 & $(0.152)$ & -0.150 & $(0.003)^{a}$ & -0.081 & $(0.075)$ \\
\hline Respondent has problems staying awake during day & -0.056 & $(0.216)$ & 0.052 & $(0.223)$ & -0.093 & $(0.046)$ & -0.058 & $(0.210)$ & -0.043 & $(0.301)$ & -0.093 & $(0.046)^{\mathrm{c}}$ & -0.028 & $(0.554)$ \\
\hline
\end{tabular}


Appendix Table 3. Robustness tests on the treatment effect of the TECHO house

\begin{tabular}{|c|c|c|c|c|c|c|c|c|c|c|c|c|c|c|}
\hline & \multirow{2}{*}{\multicolumn{2}{|c|}{$\begin{array}{c}\text { Original Regression } \\
\text { Model } \\
\end{array}$}} & \multicolumn{4}{|c|}{ Attrition Tests } & \multirow{2}{*}{\multicolumn{2}{|c|}{ Neighbourhood test }} & \multirow{2}{*}{\multicolumn{2}{|c|}{ Time of year }} & \multirow{2}{*}{\multicolumn{2}{|c|}{$\begin{array}{c}\text { Propensity score } \\
\text { matching }\end{array}$}} & \multirow{2}{*}{\multicolumn{2}{|c|}{ Falsification test }} \\
\hline & & & \multicolumn{2}{|c|}{ Upper bound } & \multicolumn{2}{|c|}{ Lower bound } & & & & & & & & \\
\hline & Coeff. & P-value & Coeff. & P-value & Coeff. & P-value & Coeff. & P-value & Coeff. & P-value & Coeff. & P-value & Coeff. & P-value \\
\hline \multicolumn{15}{|l|}{ HEALTH } \\
\hline$\geq 1$ member had frequent cough/congestion past year & -0.118 & $(0.007)^{\mathrm{a}}$ & -0.013 & $(0.785)$ & -0.157 & $(0.000)$ & -0.120 & $(0.011)^{\mathrm{a}}$ & -0.114 & $(0.008)^{\mathrm{a}}$ & -0.100 & $(0.033)^{c}$ & -0.067 & $(0.064)^{c}$ \\
\hline$\geq 1$ member had bronchitis/pneumonia past year & -0.043 & $(0.333)$ & 0.044 & $(0.279)$ & -0.103 & $(0.017)$ & -0.046 & $(0.348)$ & -0.041 & $(0.324)$ & -0.042 & $(0.400)$ & -0.053 & $(0.072)$ \\
\hline$\geq 1$ member had highly frequent joint pain past year & -0.058 & $(0.301)$ & 0.045 & $(0.407)$ & -0.098 & $(0.055)$ & -0.064 & $(0.24)$ & -0.052 & $(0.368)$ & -0.134 & $(0.007)^{\mathrm{a}}$ & -0.074 & $(0.042)$ \\
\hline$<$ age 6 with diarrhoea during past month & 0.018 & $(0.790)$ & 0.151 & $(0.018)$ & -0.037 & $(0.556)$ & 0.031 & $(0.65)$ & -0.051 & $(0.580)$ & 0.071 & $(0.146)$ & 0.004 & $(0.948)$ \\
\hline Respondent satisfied with health & 0.025 & $(0.678)$ & 0.050 & $(0.361)$ & -0.095 & $(0.140)$ & 0.025 & $(0.678)$ & 0.039 & $(0.497)$ & 0.038 & $(0.378)$ & 0.007 & $(0.883)$ \\
\hline \multicolumn{15}{|l|}{ SECURITY } \\
\hline Respondent worried about condition of dwelling & -0.447 & $(0.000)^{\mathrm{a}}$ & -0.318 & $(0.000)$ & -0.466 & $(0.000)$ & -0.454 & $(0.000)^{\mathrm{a}}$ & -0.440 & $(0.000)^{\mathrm{a}}$ & -0.521 & $(0.000)^{\mathrm{a}}$ & -0.004 & $(0.929)$ \\
\hline Respondent concerned house could collapse & -0.258 & $(0.000)^{\mathrm{a}}$ & -0.116 & $(0.018)$ & -0.266 & $(0.000)$ & -0.263 & $(0.000)^{\mathrm{a}}$ & -0.219 & $(0.000)^{\mathrm{a}}$ & -0.259 & $(0.000)^{\mathrm{a}}$ & -0.005 & $(0.902)$ \\
\hline House was robbed during the past year & -0.095 & $(0.004)^{\mathrm{a}}$ & 0.033 & $(0.418)$ & -0.111 & $(0.000)$ & -0.443 & $(0.000)^{\mathrm{a}}$ & -0.411 & $(0.000)^{\mathrm{a}}$ & -0.065 & $(0.08)^{\mathrm{c}}$ & -0.045 & $(0.077)$ \\
\hline Respondent concerned house could be occupied & -0.091 & $(0.019)^{\mathrm{a}}$ & 0.021 & $(0.594)$ & -0.132 & $(0.001)$ & -0.090 & $(0.031)^{\mathrm{b}}$ & -0.086 & $(0.066)^{b}$ & -0.040 & $(0.393)$ & 0.037 & $(0.320)$ \\
\hline Respondent feels secure in the dwelling & 0.428 & $(0.000)^{\mathrm{a}}$ & 0.443 & $(0.000)$ & 0.298 & $(0.000)$ & 0.429 & $(0.000)^{\mathrm{a}}$ & 0.417 & $(0.000)^{\mathrm{a}}$ & 0.484 & $(0.000)^{\mathrm{a}}$ & 0.015 & $(0.771)$ \\
\hline \multicolumn{15}{|l|}{ ACTIVITIES IN THE DWELLING } \\
\hline Trade or handicraft in the home & -0.004 & $(0.959)$ & 0.089 & $(0.194)$ & -0.057 & $(0.375)$ & -0.008 & $(0.913)$ & 0.000 & $(0.998)$ & 0.076 & $(0.131)$ & 0.114 & $(0.005)^{\mathrm{a}}$ \\
\hline Non-profit trade or handicraft in the home & 0.032 & $(0.387)$ & 0.156 & $(0.000)$ & 0.011 & $(0.738)$ & 0.030 & $(0.430)$ & 0.047 & $(0.360)$ & 0.038 & $(0.276)$ & 0.108 & $(0.004)^{\mathrm{a}}$ \\
\hline No tranquil place for children to study & 0.259 & $(0.000)^{\mathrm{a}}$ & 0.291 & $(0.000)$ & 0.001 & $(0.994)$ & 0.271 & $(0.001)^{\mathrm{a}}$ & 0.295 & $(0.001)^{\mathrm{a}}$ & 0.400 & $(0.000)^{\mathrm{a}}$ & 0.058 & $(0.235)$ \\
\hline \multicolumn{15}{|l|}{ INTERPERSONAL RELATIONS } \\
\hline Frequent conflict due to lack of space & -0.261 & $(0.000)^{\mathrm{a}}$ & -0.123 & $(0.039)$ & -0.275 & $(0.000)$ & -0.264 & $(0.000)^{\mathrm{a}}$ & -0.296 & $(0.000)^{\mathrm{a}}$ & -0.278 & $(0.000)^{\mathrm{a}}$ & -0.070 & $(0.036)^{c}$ \\
\hline Never receive friends in the home & -0.029 & $(0.283)$ & 0.101 & $(0.006)$ & -0.043 & $(0.084)$ & -0.031 & $(0.266)$ & -0.027 & $(0.393)$ & -0.034 & $(0.269)$ & 0.009 & $(0.705)$ \\
\hline Respondent uncomfortable receiving friends & -0.254 & $(0.000)^{\mathrm{a}}$ & -0.117 & $(0.005)$ & -0.271 & $(0.000)$ & -0.253 & $(0.000)^{\mathrm{a}}$ & -0.272 & $(0.000)^{\mathrm{a}}$ & -0.269 & $(0.000)^{\mathrm{a}}$ & -0.009 & $(0.812)$ \\
\hline \multicolumn{15}{|c|}{ PSYCHOLOGICAL WELLBEING AND PERCEPTION OF WELLBEING } \\
\hline Respondent had negative feelings last month & -0.190 & $(0.003)^{\mathrm{a}}$ & -0.118 & $(0.036)$ & -0.269 & $(0.000)$ & -0.196 & $(0.005)^{\mathrm{a}}$ & -0.154 & $(0.016)^{\mathrm{b}}$ & -0.166 & $(0.002)^{\mathrm{a}}$ & -0.028 & $(0.437)$ \\
\hline Respondent had negative feelings every day & -0.059 & $(0.411)$ & 0.072 & $(0.269)$ & -0.083 & $(0.178)$ & -0.059 & $(0.418)$ & -0.036 & $(0.603)$ & -0.061 & $(0.185)$ & -0.005 & $(0.888)$ \\
\hline Respondent feels stress due to conflict in home & -0.147 & $(0.018)^{\mathrm{b}}$ & -0.049 & $(0.412)$ & -0.201 & $(0.000)$ & -0.150 & $(0.023)^{\mathrm{b}}$ & -0.108 & $(0.079)^{\mathrm{c}}$ & -0.158 & $(0.002)^{\mathrm{a}}$ & 0.008 & $(0.811)$ \\
\hline Respondent feels stress due to conflict every day & -0.049 & $(0.322)$ & 0.088 & $(0.092)$ & -0.067 & $(0.112)$ & -0.053 & $(0.290)$ & -0.054 & $(0.341)$ & -0.054 & $(0.116)$ & -0.004 & $(0.910)$ \\
\hline Respondent has good quality of life & 0.116 & $(0.002)^{\mathrm{a}}$ & 0.124 & $(0.001)$ & -0.021 & $(0.630)$ & 0.115 & $(0.003)^{\mathrm{a}}$ & 0.146 & $(0.000)^{\mathrm{a}}$ & 0.115 & $(0.003)^{\mathrm{a}}$ & 0.017 & $(0.675)$ \\
\hline Respondent is satisfied with house & 0.532 & $(0.000)^{\mathrm{a}}$ & 0.530 & $(0.000)$ & 0.381 & $(0.000)$ & 0.523 & $(0.000)^{\mathrm{a}}$ & 0.535 & $(0.000)^{\mathrm{a}}$ & 0.527 & $(0.000)^{\mathrm{a}}$ & -0.042 & $(0.310)$ \\
\hline Respondent is comfortable in the house & 0.589 & $(0.000)^{\mathrm{a}}$ & 0.587 & $(0.000)$ & 0.438 & $(0.000)$ & 0.579 & $(0.000)^{\mathrm{a}}$ & 0.609 & $(0.000)^{\mathrm{a}}$ & 0.521 & $(0.000)^{\mathrm{a}}$ & 0.047 & $(0.261)$ \\
\hline
\end{tabular}

${ }^{a}$ Treatment dummy is statistically significant at least at the $10 \%$ level according to the Bonferroni and the Holm tests.

${ }^{\mathrm{b}}$ Treatment dummy is statistically significant at least at the $10 \%$ level according to the Holm test.

${ }^{\mathrm{c}}$ Treatment dummy is statistically significant at the $10 \%$ only before adjusting for multiple hypothesis tests. 